\title{
Empreender solidário: outra forma de conceber as relações sociais de produção
}

\author{
Kleiton Wagner Alves da Silva Nogueira ${ }^{1}$
}

Universidade Federal de Campina Grande

\section{RESUMO}

O crescimento do desemprego e a necessidade de pensar em uma outra economia possível faz da Economia Solidária uma opção para a reflexão em torno das relações sociais de produção na atualidade e de qual o papel da Administração enquanto ciência nesse contexto. Com isso, o presente artigo tem como objetivo apresentar uma reflexão sobre as relações entre a Administração Política e a Economia Solidária a partir do estudo de uma ação prática desenvolvida em uma comunidade carente do município de Campina Grande, Paraíba. Trata-se do relato de uma experiência de atividades realizadas que apresentaram como principais resultados a identificação da necessidade de maior envolvimento da academia nas comunidades e em especial o papel da Administração enquanto ciência que tem como objeto de estudo realizar reflexões a respeito da necessidade de adotar uma perspectiva mais humana no provimento das condições de existência material da sociedade. Concluiu-se que a partir das atividades realizadas se faz imprescindível a atuação do Estado por meio de parcerias com a academia brasileira para um maior aproveitamento do potencial das comunidades carentes para o próprio provimento das condições materiais.

Palavras-chave: Empreender solidário. Economia Solidária. Administração Política

\begin{abstract}
The growth of unemployment and the need to think about another possible economy make Solidarity Economy an option for reflection on the social relations of production today and the role of Administration as a science in this context. With this in mind, this article aims to present a reflection on the relations between Political Administration and Solidarity Economy based on the study of a practical action developed in a poor community in the city of Campina Grande, Paraíba. This is the report of an experience of activities carried out that presented as main results the identification of the need for greater involvement of academia in the communities and especially the role of the Administration as a science whose object of study is to carry out reflections on the need to adopt a more human perspective in providing the conditions of material existence of society. It was concluded that from the activities carried out it is essential the performance of the State through partnerships with the Brazilian academy for a better use of the potential of needy communities for the provision of material conditions.
\end{abstract}

Keywords: Undertake solidarity. Solidarity economy. Political Administration.

\section{RESUMEN}

El crecimiento del desempleo y la necesidad de pensar en una otra economía posible hacen de la economía solidaria una opción para la reflexión sobre las relaciones sociales de producción en el tiempo presente y cuál es el papel de la Administración como ciencia en este contexto. Con ello, el objetivo de este artículo es realizar una reflexión entre la Administración Política y la Economía Solidaria a través de una acción práctica desarrollada en una comunidad pobre de la ciudad de Campina Grande, Paraíba. Es un informe de una experiencia sobre las actividades desarrolladas que presentaron com principales resultados la identificación de la necesidad de una mayor participación de la academia en las comunidades y, en particular, el papel de la Administración como una ciencia que tiene la gestión como objeto de estudio para hacer reflexiones respeto de la necesidad de adoptar una perspectiva más humana en el suministro de las condiciones de la existencia material de la sociedad. Se concluyó que, con base en las actividades realizadas, es esencial que el Estado actúe a través de alianzas con la academia, a fin de aprovechar al máximo el potencial de las comunidades desfavorecidas para la provisión adecuada de condiciones materiales.

Palabras clave: Emprender solidario. Economía Solidaria. Administración Política. 


\section{Introdução}

Pensar a Administração além das relações microeconômicas é vislumbrar um universo de possibilidades para a atuação dessa ciência no seio de problemas sociais. Por meio da gestão, a Administração tem a capacidade de compreender o processo de produção, circulação e distribuição de mercadorias no modo de produção capitalista. Esse contexto nos impulsiona à reflexão de uma ciência que possa transpor o paradigma técnico-gerencial, considerando assim, a esfera política existente não apenas nas organizações, mas também na sociedade de uma forma total. Nesse sentido, é possível enxergar a Administração Política como uma forma de pensar e problematizar a realidade social, principalmente, em tempos de crise estrutural do capitalismo.

De acordo com Santos (2010), a sociedade brasileira encontra-se insatisfeita com a produção e a distribuição propiciadas pelo mercado, caracterizadas pela concentração de renda e pela incapacidade desse mercado atender demandas reprimidas, o que se materializa sob a forma de segregação e exclusão social. Essa constatação abre espaço para a reflexão em torno dos modelos de gestão adotados no país, especificamente, sobre a forma como a Administração está sendo aplicada para a formação de um projeto de nação que consiga suprir as demandas da sociedade diante do atual dinamismo do capitalismo.

Outro elemento subjacente a essa dinâmica reside nas constantes crises e superações de limites do capitalismo ao usar o Estado como hospedeiro para a legitimação de atos políticos que subordinam os interesses coletivos ao mercado. Dessa forma, não se trata de um Estado fraco ou ausente, pelo contrário, essa realidade implica um Estado atuante frente aos interesses do capital e ausente com relação às políticas sociais (Kowarick, 1985; Santos, 2010; Valim, 2017).

No Brasil, essa relação de um Estado para o Capital aparece de forma mais intensa a partir da década de 1990 por meio de políticas econômicas de curto prazo. Essa década foi fortemente marcada pela reestruturação produtiva da economia brasileira e pelas políticas de austeridade fiscal com redução da ação estatal em setores estratégicos (Santos, Gomes, 2017). Com esse cenário, o quadro de desemprego ocasionado pela reestruturação produtiva dessa época abriu espaço para práticas como da Economia Solidária, ou seja, outra forma de realizar a produção social a indivíduos que estavam à margem da economia formal. Essa outra forma possibilita a promoção de trabalho com base em princípios da solidariedade, cooperação e autogestão (Bertucci et al.,2009; Gaiger, 2009; Singer, 2010).

É possível observar que a década de 1990 não está totalmente distante do atual cenário político e econômico do país. O Instituto Brasileiro de Geografia e Estatística (IBGE) observa que, em 2015, o país apresentou uma taxa de desocupação de 7,9\% para os homens e 11,8\% para as mulheres. Em Campina Grande, que é o lócus de reflexão deste artigo, o município apresentou uma taxa de desemprego de 10,74\% em 2016. Isso representa uma queda de 16,27\% nos postos de trabalho em relação ao ano de 2015 segundo dados do Cadastro Geral de Empregados e Desempregados (CAGED).

Com base nesse cenário, este artigo tem por objetivo realizar uma reflexão entre a Administração Política e a Economia Solidária. Trata-se de um estudo descritivo e exploratório que se utiliza da revisão bibliográfica e do relato de experiência como atividades intermediadoras para o alcance do objetivo proposto. Dessa forma, o relato que procuramos expor trata-se de uma experiência local de empreendedorismo solidário, na qual se buscou fomentar práticas de Economia Solidária. Essa ação foi desenvolvida pelo Programa de Educação tutorial em Administração da Universidade Estadual da Paraíba (PET Administração UEPB) em uma comunidade carente do município de Campina Grande, Estado da Paraíba.

Com base nesses elementos, o artigo está dividido em quatro partes principais: na primeira parte, é realizada a caracterização da Administração enquanto ciência a desempenhar um papel de reflexão crítica acerca das relações sociais de produção; posteriormente, procuramos discutir a cerca da economia solidária como uma forma de materialização de outro modo de conceber as relações de produção no capitalismo; em um terceiro momento, explicitamos a metodologia utilizada no trabalho e finalizamos o artigo realizando ponderações em torno de uma experiência de extensão universitária de modo a 
compreendermos melhor qual o papel da Administração no desenvolvimento de contextos locais.

\section{Por uma Administração crítica das relações sociais de produção}

$\mathrm{Na}$ perspectiva holística, é inconcebível pensar a Administração como não fazendo parte do rol de ciências sociais aplicadas. Pelo contexto histórico, seu nascimento como "ciência" pauta-se na microeconomia por meio da necessidade de práticas e técnicas gerenciais oriundas da revolução industrial inglesa (Cristaldo, 2009).

Entretanto, ao considerar a própria história da humanidade, é possível enxergar que o ser humano, desde os primórdios de sua existência, precisou realizar atividades típicas da Administração: planejar; organizar; dirigir e controlar. A exemplo, temos grandes civilizações como a Egípcia e a Romana que em suas formas de organização social se utilizaram da Administração (Silva; Lopes, 2009; Silva; Silva, 2013). Todavia, o status científico da Administração pode ser ligado à forma como o capitalismo necessitou de uma ciênciainstrumento para a gerência de elementos produtivos nas organizações capitalistas; desse ponto de vista, as organizações seriam o objeto de estudo desta ciência.

Contudo, o presente estudo parte do pressuposto que a Administração como ciência vai além das organizações por ter a gestão como seu objeto de estudo; essa ciência consegue, portanto, ultrapassar relações microeconômicas para contribuir no entendimento das relações sociais de produção:

E o que cabe, então, à administração? Pura e simplesmente, a gestão. Assim, cabe à administração estruturar um modelo de gestão viabilizador do objetivo da organização. Portanto, a gestão é apenas um dos conteúdos que dão institucionalidade e essência às organizações. Então, podemos concluir que é a gestão, e não a organização, que caracteriza o objeto e que dá autonomia à administração como um campo próprio do conhecimento (Santos, 2009, p.43, grifo nosso).

Apreender a gestão como objeto de estudo da Administração torna-se essencial no entendimento da relação entre Estado, organizações e sociedade. A organização pode ser objeto de pesquisa de várias ciências, redimensionar esse objetivo à Administração implica em um pauperismo teórico, tendo em vista que se estaria elencando o papel dessa ciência à mera análise técnica ${ }^{2}$, desconsiderando assim, a vertente política presente nas organizações e na sociedade como um todo.

Nesse contexto, Ribeiro (2006) levanta a noção de que a Administração é uma ciência social e que o Administrador é mais do que um simples executor de tarefas pré-definidas. Para o autor, esse profissional deve ir além dos aspectos gerenciais e prescritivos para que então, se insira no âmbito da gestão.

Nesse sentido, pode-se constatar que, mesmo sob o nascedouro de uma matriz gerencial, a Administração acaba sendo chamada a pensar os problemas da humanidade, principalmente, aqueles ligados à perspectiva da gestão, ou seja, a necessidade de um olhar mais aprofundado sobre os problemas relacionados à dinâmica das relações Capital, Estado e Sociedade faz com que essa ciência não desconsidere a variável política inerente às relações humanas e sociais.

Segundo Santos (2009), se a Economia Política se preocupa com o quê e por que produzir, ou seja, pelas possibilidades da produção, da circulação e de distribuição de bens materiais, a Administração Política deve se preocupar em "como" fazer, quer dizer, na concepção do modelo de gestão capaz de conceber a materialidade da produção humana.

Nesse ponto de reflexão em específico, ligado à esfera da gestão, pode-se visualizar o papel social a ser desempenhado pelo Administrador. Para Cristaldo (2009), há um pensamento coletivo em torno da Administração que liga essa ciência a um conjunto abstrato de técnicas e prescrições a serem seguidas na busca por eficiência, por eficácia e por

\footnotetext{
${ }^{2}$ É importante destacar que não há possibilidade de conceber a Administração enquanto uma ciência meramente teórica; para Santos (2009), há o aspecto profissional da

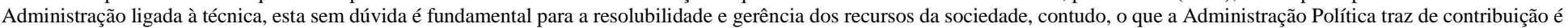

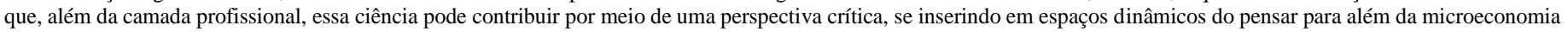


efetividade. Para além dessa interpretação, faz-se necessário a superação dessa visão reducionista que caracteriza a atividade do administrador como mero aplicador de práticas gerenciais.

Ainda de acordo com esse autor, são três as principais funções sociais do administrador:

[...] (1) a de controlar a utilização dos recursos dentro das unidades de produção/distribuição da sociedade; (2) a de gerir a inserção da firma no espaço societário através de uma estratégia empresarial; e (3) a de oferecer uma abordagem do fato socioeconômico que compreenda suas nuanças complexas de gestão, estendendo-se das relações de trabalho à produção, distribuição e poder (Cristaldo, 2009, p.46).

Assim como Santos (2009), Cristaldo (2009) enxerga que a Administração tem a capacidade de ação sobre a produção da materialidade humana de forma concatenada com a Economia Política. Nesses termos, a função do administrador não seria apenas o da criação e da medição do tamanho da distribuição da riqueza social, mas também, sobretudo, a atividade de como criar riqueza e distribuí-la de forma equânime para a promoção do bemestar social coletivo.

Conforme Gonçalves (et. al. 2013), essa finalidade social estaria ligada ao atendimento das demandas inerentes à materialidade humana; diante disso, surge a necessidade de construção de um modelo de gestão que consiga atender essas demandas de forma a contemplar não apenas o consumo, mas também uma forma de sociabilidade que harmonize os pilares econômicos, sociais e naturais.

A partir desta perspectiva, é possível refletir sobre uma forma de "como fazer" essa nova gestão não ligada diretamente à geração do lucro, expropriação do trabalho dos indivíduos e alienação do trabalhador. Desse modo, é possível visualizar o campo da Economia solidária como uma alternativa a essas formas de exploração.

\section{Economia solidária e a iminência de uma perspectiva humana nas relações sociais de produção}

De acordo com Brasil (2015), a economia solidária é um modo diferente de produzir, vender, comprar e trocar. Na Economia Solidária, os trabalhadores são detentores dos meios de produção. Sendo assim, esses indivíduos conquistam a possibilidade de tomar decisões sobre o negócio realizado, dividindo o trabalho e partilhando os resultados da atividade desenvolvida.

A Economia tradicional, por sua vez, dimensiona a produção a partir da separação da classe trabalhadora e os detentores dos meios de produção, inexistindo assim, repartição dos lucros obtidos; pelo contrário, há uma apropriação do excedente de trabalho produzido pelos trabalhadores por meio do processo de mais-valia (Marx, Engels, [1848] 2009).

Segundo Brasil (2015), a economia solidária possui determinadas características como se pode observar na figura a seguir:

Figura 01: Características da Economia Solidária 


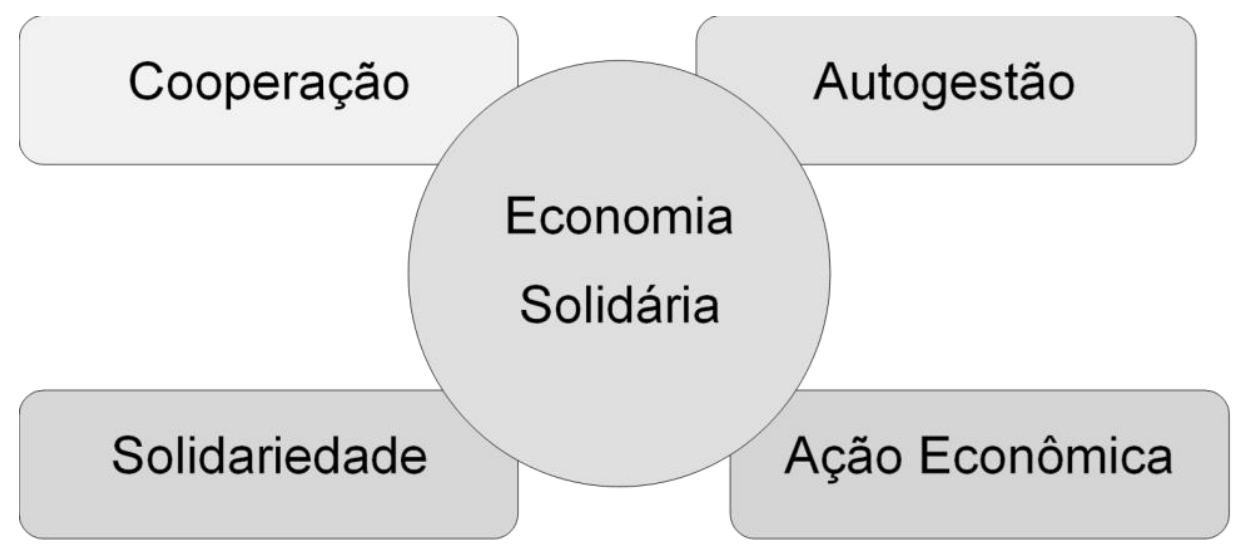

Fonte: Elaboração do autor com base em Brasil (2015).

Desse modo, na cooperação os indivíduos não se enxergam como competidores ou adversários. Todos trabalham a partir da noção de coletividade dos meios de produção para o alcance de um objetivo geral que atenda a todos com a partilha dos resultados. Há também a tomada de decisão em grupo e de forma horizontal. Os indivíduos realizam a autogestão por meio da participação democrática. Cabe destacar que a ação econômica desses empreendimentos solidários realiza a produção, a comercialização, a prestação de serviços, as trocas e o acesso ao crédito e o consumo. Por último e não menos importante, a solidariedade como um pressuposto básico desse tipo de economia, em si, implica na preocupação com os outros indivíduos ao buscar uma distribuição mais igualitária e equânime dos resultados (Bertucci et al.,2009; Singer, 2010).

Com base em Bertucci (2009), é possível desvelar que, no movimento dialético e contraditório do Capital, o surgimento de crises acentua as desigualdades sociais, gerando, em cada crise, uma onda massiva de desempregados e de empobrecimento crônico das populações em diferentes territórios. Para esta autora, uma forma de solucionar esses problemas se daria através da promoção de uma Economia baseada na solidariedade, que leve em consideração a valorização da cooperação, da responsabilidade coletiva e compartilhada em favor da construção de uma sociedade mais justa.

Portanto, a Economia Solidária traz, em seu bojo, uma forma contra-hegemônica ao modelo de sociedade dominante, sendo assim, caracteriza-se como alternativa e outro modo de pensar a organização da sociedade ${ }^{3}$. Dessa maneira, a Economia solidária prioriza o desenvolvimento que não seja baseado nas grandes empresas nem nos latifúndios com seus proprietários e acionistas, mas um desenvolvimento para as pessoas e construída pela população a partir dos valores da solidariedade, da democracia, da cooperação, da preservação ambiental e dos direitos humanos.

É, na década de 1980, que surgem as primeiras experiências de Economia Solidária no Brasil, reflexo do desemprego provocado pela crise cambial e inflacionária da época. Nesse período, a Cáritas brasileira, organização ligada à Conferência Nacional dos Bispos do Brasil (CNBB) criou o programa de projetos alternativos comunitários (PACs) com o intuito de financiar e capacitar pessoas desempregadas para o trabalho autônomo (Pitaguari, Camara, Santos, 2012).

Devido ao contexto de crise e de falência de empresas, muitos trabalhadores conseguiram, na justiça, o direito de assumir essas empresas com o objetivo de recuperá-las em forma de cooperativas autogestionárias. Essas experiências implicaram na criação da Associação Nacional dos Trabalhadores em Empresas de Autogestão e Participação Acionária (ANTEAG) e da União e Solidariedade das Cooperativas do Estado de São Paulo (UNISOL).

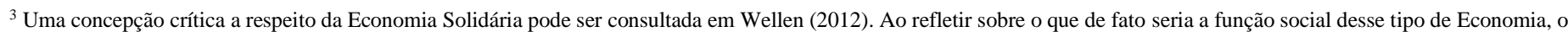

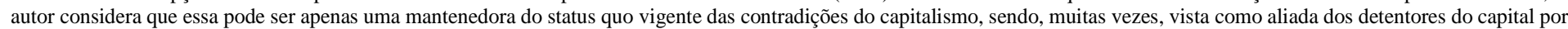
acalentar o exército de reserva construído pelos processos de reestruturação produtiva.
} 
Em âmbito rural, o Movimento dos Trabalhadores sem Terra (MST) apoiou a economia solidária através da formação de cooperativas agrícolas autogestionárias em contraposição às cooperativas tradicionais de cunho capitalista (Bertucci et al.,2009; Lima; Souza, 2014; Pitaguari; Camara; Santos, 2012).

Outra contribuição para os empreendimentos solidários no Brasil parte das Incubadoras Tecnológicas de Cooperativas Populares (ITCPs). A primeira dessas incubadoras foi criada em 1995 através do Instituto Alberto Luiz Coimbra de Pós-Graduação e Pesquisa de Engenharia (COPPE) da Universidade Federal do Rio de Janeiro (UFRJ). Outro apoio partiu da Central Única dos Trabalhadores (CUT), essa organização criou em 1999 a Agência de Desenvolvimento Solidário (ADS); desde então, essa agência tem difundido conhecimento sobre Economia Solidária por meio de cursos relacionados a lideranças sindicais e militantes, capacitando pessoas em cursos de pós-graduação. Com relação ao aporte do Estado através de políticas públicas, a cidade de Porto Alegre apresenta pioneirismo. Em 1994, na Administração de Olívio Dutra, foi lançada em nível estadual a primeira política de a poio à economia solidária. É possível constatar que, por intermédio dos programas de economia solidária, o poder público passou a dar apoio para que os desempregados montassem seu próprio negócio ou cooperativas. De maneira geral, essas iniciativas forneceram subsídios para um patamar de reconhecimento por parte do governo federal acerca da Economia Solidária (Pitaguari; Camara; Santos, 2012).

Em um contexto mais recente, no primeiro mandato do governo Lula, foi criada a Secretaria Nacional de Economia Solidária (SENAES). Essa secretaria tem como função realizar a articulação e organização de políticas federais de apoio à economia solidária, incentivando também que essas políticas sejam construídas em escala municipal e estadual (Ortigoza, 2014).

Como uma forma de orientar as ações da SENAES, também foi criado o Conselho Nacional de Economia Solidária (CNES), que tem por função propor diretrizes relacionadas a ações de economia solidária nos ministérios e órgãos do governo federal, como também, realizar o acompanhamento da execução dessas ações. Outro importante movimento de fomento à Economia Solidária se deu pela iniciativa do governo federal com a criação do Fórum Brasileiro de Economia Solidária (FBES) em 2003. Esse fórum tem realizado ações no sentido de apoiar o movimento em favor da economia solidária, sendo também um estímulo a programas estaduais e municipais em economia solidária (Pitaguari, Camara, Santos, 2012).

É importante destacar que as experiências relacionadas à Economia Solidária no Brasil ligam-se ao fenômeno do desemprego estrutural no capitalismo contemporâneo. Para Singer (2010), esse fato é preponderante no surgimento dessa modalidade de Economia no país. Doravante, essas possibilidades e empreendimentos solidários partem da ótica de uma lacuna no mercado, que, em princípio, implica na possibilidade de inserção de comunidades e empreendimentos solidários para o atendimento de demandas reprimidas ou não percebidas pelo mercado.

Ainda segundo Singer (2010), para que essas comunidades identifiquem oportunidades de inserção, faz-se necessária a presença dos agentes de desenvolvimento que apresentam por função facilitar o processo de organização do empreendimento e da análise dos aspectos ligados ao mercado como oportunidades. Os agentes podem ser bancos públicos, serviços públicos e agências de fomento da economia solidária ligadas à Igreja Católica, sindicatos ou universidades.

Nesse sentido, a capacitação das pessoas que residem em comunidades carentes tornase essencial para o desenvolvimento de atividades solidárias e de fomento à criação de cooperativas. O ideal em si é instigar que a comunidade se capacite para o enfrentamento de contingências em torno do negócio a ser desenvolvido. A esse modo, os agentes de desenvolvimento podem realizar atividades que induzam a comunidade no trabalho com informações referentes à atividade que realizarão, como também, deve haver, de acordo com Singer (2010), uma troca de saberes entre os agentes e a própria comunidade, uma vez que deve existir para esse autor, um relacionamento constante e igualitário entre as partes.

Ademais, é preciso considerar as fragilidades das comunidades e a complexa tarefa de desenvolver atividades de empreendimento solidário, principalmente, à luz do atual modelo de produção capitalista, em que a individualidade é, acima de tudo, vista como uma 
característica importante para a sobrevivência humana.

Contudo, Singer (2010) salienta que uma forma de vencer as fragilidades relacionadas à inserção de atividades de cunho solidário em comunidades carentes se daria através da presença do Estado por meio de escolas de Administração Federal, Estadual e Municipal. Nesse contexto, surgiu no Programa de Educação Tutorial do curso de Administração da Universidade Estadual da Paraíba (PET Administração UEPB) a necessidade de estender a Administração para além das relações microeconômicas e técnicas presentes nos manuais e na sala de aula.

Parte-se do pressuposto de que os conhecimentos adquiridos na Universidade podem desenvolver um papel dentro de comunidades carentes por meio do processo educativo de fomento à economia solidária; sendo esse processo pensando em uma forma pedagógica de mão dupla, por meio da qual os alunos contribuem com conhecimentos da Administração adquiridos na Universidade e, em contrapartida, a comunidade também ajudaria esses alunos a entenderem e a visualizarem aspectos contidos na realidade, que não são possíveis de serem observados dentro dos muros da Universidade.

Dessa forma, o tópico a seguir apresenta caracteristicas de uma ação desenvolvida pelos integrantes do PET Administração UEPB pertencentes ao projeto de extensão desenvolvido pelo grupo "Empreender solidário: transformando para uma melhor qualidade de vida" em uma comunidade do município de Campina Grande, Paraíba.

\section{O projeto empreender solidário: uma forma de estímulo à economia solidária}

O projeto Empreender Solidário surgiu a partir de uma iniciativa do PET Administração UEPB em conjunto ao departamento de Química dessa mesma instituição de ensino. O objetivo central do projeto é capacitar pessoas que residem em comunidades carentes para que essas adquiram conhecimento e criem ações voltadas para a Economia solidária. A ação apresentada neste artigo foi realizada em uma comunidade ${ }^{4}$ periférica do município de Campina Grande, Paraíba.

Em um primeiro momento referente à etapa de escolha da comunidade a ser atendida, partiu-se da problemática lançada no projeto: o atendimento a comunidades que apresentam elevados níveis de pobreza. Com isso, o primeiro contato com a comunidade se deu pela Associação de Moradores de bairro. Nesse contato, foi possível saber de forma mais detalhada a demanda da comunidade, a quantidade de pessoas disponíveis para a realização da ação, a disponibilidade de local apropriado para execução das oficinas e o agendamento de reunião com a comunidade para a explicação da ação. Optou-se por redimensionar a ação apenas para mulheres, uma vez que essas possuem maiores dificuldades de inserção no mercado de trabalho, como também, são vulneráveis a situação de dependência econômica e violência.

Conforme dados do ano de 2010 do Atlas Brasil referentes ao município de Campina Grande, cerca de $40 \%$ das mulheres entre 18 a 24 anos de idade não estudam, não trabalham e são vulneráveis, contra $25 \%$ dos homens. Essa discrepância aumenta quando os dados apontam que a taxa de desocupação das mulheres em idade de 25 a 29 anos gira em torno dos 18\% das mulheres contra 8\% dos homens (Atlas Brasil, 2013).

Além desses elementos, há outros problemas referentes à própria reprodução da mulher no seio social. Pode-se elencar uma série de temas ligados aos desafios enfrentados pela mulher como: inserção marginal no mercado de trabalho; ascensão e conquistas de direitos em conjunto com uma dupla jornada de trabalho; assédio no ambiente de trabalho, construção social da mulher como provedora de atividades domésticas (Hirata, 2002; 2009; 2010).

Nesse sentido, ao todo, foram atendidas cerca de trinta pessoas, sendo em sua maioria mulheres, donas de casa e aposentadas. Entretanto, no decorrer do curso foi possível ver o interesse de dois homens em participar das ações, sendo esses dois desempregados ou

${ }^{4}$ Por motivos de ética e sigilo de informações não será exposto nesse trabalho o nome da comunidade e nem o nome das pessoas envolvidas no 
inseridos no setor informal da Economia. O segundo encontro na comunidade tinha o intuito de explicar as atividades a serem desenvolvidas, assim como a realização de cadastro dos participantes. Nessa ocasião, foi possível confirmar o número real das pessoas interessadas no projeto e a disponibilidade de dia e de horário para a realização do projeto.

Com a finalização dessas etapas, partiu-se para o planejamento das atividades e da preparação da logística. O planejamento foi realizado de maneira participativa com todos os integrantes do PET, emitindo opiniões a respeito das melhores possibilidades de execução da atividade, conteúdos a serem abordados nas oficinas e compra dos materiais de química.

Nesse contexto, como a ação foi desenvolvida em parceria com o departamento de Química da UEPB, as oficinas referentes à preparação dos materiais de limpeza ficaram sob a responsabilidade de duas professoras e de dois monitores desse departamento. Ao total, foram planejadas três oficinas de Química: a) produção de detergente; b) produção de água sanitária e c) produção de desinfetante.

A ideia central era capacitar essas pessoas em nível técnico, de produção desses materiais para após essa etapa, ser debatida a perspectiva da economia Solidária na comunidade. Dessa forma, além das oficinas relacionadas à preparação dos materiais, a comunidade também recebeu oficinas relacionas à Administração e à formulação de um projeto voltado para a Economia Solidária.

As oficinas de Administração, por sua vez, foram planejadas com o cuidado de passar os conteúdos da maneira mais didática possível. Para os petianos, esse acabou tornando-se um dos maiores desafios: transformar conteúdos vistos em sala de aula para ministrá-los a uma comunidade de forma clara e objetiva. Desse modo, foram planejadas três oficinas de Administração: a) marketing; b) empreendedorismo e economia solidária e c) finanças.

Realizada essas etapas de contato e planejamento, partiu-se para a execução de fato da atividade. Essa execução foi realizada em um período de três dias subdividido da seguinte forma: dois dias para as oficinas de Química e um dia para as oficinas de Administração.

\section{Aprender fazendo e ensinando}

As atividades do primeiro e segundo dia do projeto foram realizadas no laboratório de Química da Universidade Estadual da Paraíba no período da tarde. É importante destacar que todas as pessoas que participaram dessas oficinas de Química receberam equipamento de proteção individual (EPI) além de instruções sobre segurança e manuseio de componentes químicos.

Sendo assim, no primeiro dia, foram realizadas as seguintes oficinas: a) produção de água sanitária e b) produção de desinfetante. Dessa forma, foi importante observar que, de início, os participantes se sentiram um pouco tímidos pelo fato de que, para muitos deles, aquele foi o primeiro contato com uma instituição de ensino superior. Contudo, com a didática utilizada, foi possível fazer com que a comunidade ficasse mais confortável no ambiente e consequentemente para o exercício das atividades propostas.

Sem desconsiderar a relevância dos conteúdos ministrados nessa ação, entende-se que a própria comunidade possui um conhecimento e experiências de vida e que a academia não é a detentora do saber absoluto. Com isso, adota-se a perspectiva de reconhecer que o processo de aprendizagem é caracterizado por uma via de mão dupla e crítica por problematizar a respeito da realidade da própria comunidade (Freire, 1996).

No segundo dia, foi realizada a produção de detergente. Por tratar-se de um processo mais detalhado, optou-se por disponibilizar apenas uma tarde para o desenvolvimento dessa oficina. Destaca-se que a comunidade dominou a técnica de produção de forma rápida e sem maiores problemas. Salienta-se que a metodologia utilizada de "aprender fazendo e ensinando" foi de suma importância para a realização do processo de aprendizagem e fixação dos conteúdos.

Com base nessa lógica, os participantes das oficinas assim aprendiam determinado procedimento, repassavam o que foi aprendido aos outros colegas com a supervisão de monitores e professores. O intuito era justamente dar uma maior autonomia a essas pessoas, 
mostrar que elas também são detentoras de saber e podem contribuir com a aprendizagem dos colegas.

Figura 02: Moradores recebendo instruções sobre os produtos químicos
Figura 03: Processo de produção dos Materiais de limpeza

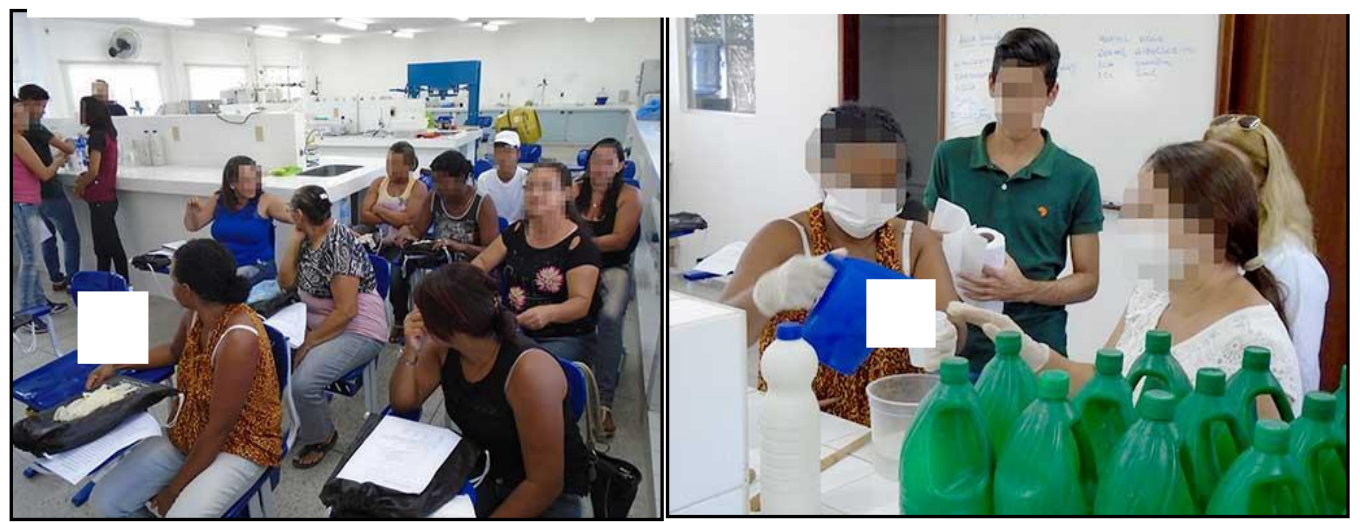

Fonte: Elaborada pelo autor

Fonte: Elaborada pelo autor

No terceiro dia de atividade tivemos as oficinas de Administração. A primeira oficina trabalhou aspectos relacionados aos custos dos produtos, formação de preço de venda e controle das despesas. De forma participativa, a comunidade dialogou e prestou atenção nos conteúdos ministrados. A segunda oficina de Administração abordou a importância do marketing como ferramenta para a promoção e melhoramento da imagem do produto fabricado pela comunidade. Já a terceira e última oficina trataram de alguns elementos e características das atividades empreendedoras, colocando em evidência a perspectiva da Economia Solidária.

É importante destacar que, no decorrer dessas oficinas, foram mostrados os limites, as dificuldades e os desafios em se trabalhar na perspectiva da economia solidária. Contudo, esses destaques apenas reforçaram o papel da união e da solidariedade para o fomento de uma atividade econômica em coletividade, sem exploração do homem pelo homem e que traga em si uma ideia de emancipação da comunidade frente aos desafios impostos ao mercado.

Dessa forma, pontos como solidariedade, autogestão e cooperação foram abordados de forma a mostrar a relevância da Economia Solidária para essa comunidade. Como aspecto adicional às oficinas de Administração, também tiveram como ponto de reflexão a possibilidade de criação de uma cooperativa de produção de materiais de limpeza que levasse em consideração princípios da economia Solidária.

As atividades desse terceiro dia podem ser observadas nas imagens seguintes:

Figura 04: Realização das oficinas de Administração

Figura 05: Dinâmicas de grupo



Fonte: Elaborada pelo autor

Fonte: Elaborada pelo autor 
Com base nesse relato, observa-se que a perspectiva adotada neste trabalho reafirma o valor da Universidade pública brasileira como pertencente à própria sociedade. Devido a esse fator e sem perder o foco na indissociabilidade entre ensino, pesquisa e extensão, constata-se que ações dessa envergadura proporcionam troca de experiências mútuas e preparam os alunos para serem profissionais mais comprometidos com a sociedade.

Para além dos modelos administrativos pautados da eficiência, da eficácia e da efetividade, entende-se que há, na sociedade, interesses que permeiam o campo político e distanciam a academia da comunidade.

\section{Considerações finais}

Por meio da atividade realizada, foi possível vislumbrar a Administração como uma promotora do desenvolvimento local ao incentivar a prática da Economia solidária em um período de recessão econômica e de alta taxa de desemprego.

Entretanto, essa Administração que possui a preocupação de olhar a realidade em sua essência, ao não encobrir os fatos sociais por meio de modelos e manuais, apresenta-se por uma perspectiva política à medida que entende que a sociedade é formada por uma complexa imbricação de interesses de classe. Ao observar a Economia solidária como uma alternativa à Economia tradicional, pode-se interpretar essa outra possibilidade como um meio de assegurar os meios de existência da sociabilidade humana além da perspectiva do lucro e da acumulação de capital.

Nesse sentido, entende-se que em consonância com demandas de longo prazo como a própria concepção de um projeto de nação (Santos \& Souza, 2017), este trabalho adota também a perspectiva de que a Administração Política brasileira pode considerar o empreendimento solidário através de uma Economia solidária como práxis de uma ação modificadora das relações sociais de produção no modo de produção capitalista, que possui como centro o rompimento da relação engendrada pela geração de mais-valor derivado da exploração da força de trabalho.

Ao mesmo tempo, salienta-se a importância do ambiente acadêmico brasileiro se inserir de forma mais intensa por meio da extensão universitária na promoção de atividades que beneficiem comunidades para além do academicismo.

Destaca-se também a necessidade de parcerias junto à administração pública para o aprimoramento de experiências dessa modalidade. Essa seria uma forma de aproveitamento de todo o potencial criativo e empreendedor presente nas comunidades carentes, mas, para que isso venha a ocorrer, faz-se imprescindível a presença do Estado no fomento desses empreendimentos, seja subsidiando apoio logístico, seja por meio de parcerias institucionais com a academia.

Esta reflexão permite concluir que, se uma outra economia é possível, também uma "outra Administração é possível" para agenciar esforços de cooperação humana na produção de bens e serviços.

\section{Referências Bibliográficas}

Atlas Brasil. (2013). Atlas do Desenvolvimento Humano no Brasil. PNUD. Recuperado de: http://www.atlasbrasil.org.br/2013/pt/ranking

Bertucci, A., Lima, C., Tygel, D., Nagem, F., Amorim, R., Souza, R. P., Kirsch, R., Bertucci, S. S. (2009) Economia Solidária: outra economia a serviço da vida acontece. Recuperado de: http://base.socioeco.org/docs/cartilha_fbes.pdf Brasil (207). Ministério do trabalho. Economia Solidária. Recuperado de: http://trabalho.gov.br/trabalhador-economia-solidaria/o-que-e

Brasil. (2015). Ministério do trabalho. Economia Solidária, 2015. Recuperado de: http://trabalho.gov.br/trabalhador-economia-solidaria/o-que-e 
Política, v. 2, n. 1. Recuperado de: https://portalseer.ufba.br/index.php/rebap/article/view/15491

Freire, P. (1996). Pedagogia da autonomia: saberes necessários à prática docente. São Paulo: Paz e Terra.

Gaiger, L. I. (2009). Antecedentes e expressões atuais da economia solidária. Revista Crítica de Ciências Sociais, v. 84, p. 81-99. Doi: 10.4000/rccs.401

Gonçalves, G. A. C., Medeiros Júnior, G., Morais, L. C. M., Martins, P. E. M. Sousa, S. M. A. (2013). O Papel Social do Administrador: Formação e Perspectivas à Luz da Administração Política. In: IV Encontro de Administração Política para o Desenvolvimento do Brasil, 2013, Vitória da Conquista - BA. ANAIS. Recuperado de: http://www.uesb.br/eventos/encontroadministracaopolitica/artigos/EAP045.pdf

Hirata, H. (2002). Globalização e divisão sexual do trabalho. Cadernos Pagu, (17-18), 139-156. https://dx.doi.org/10.1590/S0104-83332002000100006

Hirata, H. (2009). A precarização e a divisão internacional e sexual do trabalho. Sociologias, (21), 24 41. doi: https://dx.doi.org/10.1590/S1517-45222009000100003

Hirata, H. (2010) Novas configurações da divisão sexual do trabalho. Revista Tecnologia e Sociedade

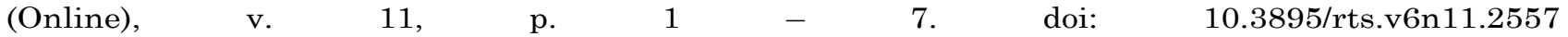
https://portalseer.ufba.br/index.php/rebap/article/view/15491/

Kowarick, L. (1985). Capitalismo e marginalidade na América Latina. 4ª ed. Rio de Janeiro, Paz e Terra.

Lima, J.C \& Souza, A.R. (2014) Trabalho, solidariedade social e economia solidária. Lua Nova: Revista de Cultura e Política, (93), 139-168. Doi: https://dx.doi.org/10.1590/S0102-64452014000300006

Marx, K., Engels, F. ([1848] 2009). Manifesto do partido comunista. São Paulo: Editora Escala.

Ortigoza, S.b (2014). Vamos privilegiar os mais fracos: a economia solidária brasileira como possibilidade de (re)inserção do território como base do desenvolvimento. Revista de Geografia e Ordenamento do Território (GOT), n. 6 (dezembro). Centro de Estudos de Geografia e Ordenamento do Território, p. 241-257

Pitaguari, S. O. Camara, M.R.G., Santos, L. M. L. (2012) Panorama da Economia Solidária no Brasil. In: Pitaguari, S. O., Cordeiro, S. M. A., Lanza, L. M. B. (Org.). A Sustentabilidade da Economia Solidária: contribuições multidisciplinares. Londrina: Universidade Estadual de Londrina - UEL, p. 33-61.

Ribeiro, J. U. (2006). Política e administração. Organizações \& Sociedade, 13(37). Recuperado de: https://portalseer.ufba.br/index.php/revistaoes/article/view/10854

Santos R. S. (2010). Manifesto da Administração Política para o Desenvolvimento do Brasil. Revista Brasileira de Administração Política, v. 3, p. 11-40. Recuperado de: https://portalseer.ufba.br/index.php/rebap/article/view/15540

Santos R. S. S., Gomes, F. G. (2017) Outro modo de interpretar o Brasil - ensaios de uma Administração Política: Caminhos para a construção do projeto nacional. São Paulo: Hucitec.

Santos, R. S. (2009). Em busca da apreensão de um conceito para administração política. In: Santos, R. (Org). Administração Política como campo do conhecimento. São Paulo-Salvador: HucitecMandacaru, p. 23-61.

Silva, D.A., Lopes, P.F.S. (2009). O papel do Administrador: administrar, gestar ou gerir.? Revista Brasileira de Administração Política, v. 2, n. 2. Recuperado de: https://portalseer.ufba.br/index.php/rebap/article/view/15502/10643

Silva, R. O., Silva, R.O. (2013). Teorias Administrativas. 3.ed. São Paulo: Pearson Education do Brasil.

Singer, P. (2010). É possível levar o desenvolvimento a comunidades pobres? In: TORRES, I.C (org). As malhas do trabalho e da economia solidária no Brasil. Manaus: Edua.

Valim, R. (2017). Estado de exceção: a forma jurídica do Neoliberalismo. São Paulo: Editora contracorrente.

Wellen, H. (2012). Para a crítica da economia solidária. São Paulo: Outras expressões. 